\title{
Solid reactant-based geopolymers from rice hull ash and sodium aluminate
}

\author{
Ailar Hajimohammadi and Jannie S. J. van Deventer ${ }^{\mathrm{b}, \mathrm{c}}$ \\ ${ }^{a}$ Department of Infrastructure Engineering, University of Melbourne, Victoria 3010, Australia \\ ${ }^{b}$ Department of Chemical and Biomolecular Engineering, University of Melbourne, Victoria 3010, Australia \\ ${ }^{c}$ Zeobond Pty Ltd, P.O. Box 23450, Docklands, Victoria 8012, Australia
}

High carbon rice hull ash and solid sodium aluminate were used as silica, alkali and alumina sources to synthesise one-part "just add water" geopolymer binders. Three binders with different Si/Al ratios and different water contents were studied. Due to the high carbon content of the samples, using a high amount of water is required to satisfy the workability of the binders. Similar to traditional geopolymer systems, high water content increases the crystallinity, decreases the reaction rate and negatively affects the microstructure of samples. In high carbon rice hull ash system, silica concentration is not a suitable indication of the silica availability for reaction, and the amount of unburned carbon in ash particles affects silica release rate. Increasing the silica content of raw materials leads to higher amount of Si/Al ratio in the final geopolymer binder and improves the mechanical and microstructural properties of samples. All samples studied here successfully made geopolymer binders. The highest strength achieved was $22 \mathrm{MPa}$ after three weeks.

\section{Introduction}

The reaction of solid aluminosilicate materials with a highly alkaline hydroxide or alkali-metal silicate solution can result in the production of an amorphous to semi-crystalline three-dimensional aluminosilicate material commonly called a 'geopolymer'[1]. Geopolymeric materials have potential in many applications because of their unique properties, such as their high resistance to elevated temperatures and fire, and high resistance to acid and salt environments [2]. Additionally, their production results in greatly reduced $\mathrm{CO}_{2}$ emissions compared to the use of Portland cement in concretes [3]. These advantages are the main motives for the growth in research on the development of various environmentally friendly alkali-activated construction materials [4].

Soluble silicates are known to have a remarkable influence on the dissolution behaviour and precipitation characteristics of geopolymers, by enhancing alkali-metal attack on aluminosilicate particles and 
consequently accelerating geopolymer formation $[5,6]$. It is also known that using a silicate activating solution rather than a hydroxide can increase the strength of geopolymeric binders [7], and its concentration can have a controlling effect on geopolymer strength and microstructure [8].

However, using viscous and corrosive sodium silicate solutions for the bulk production of geopolymers is restrictive in the commercial application of these binders. Although heating can be useful in decreasing the viscosity of these activators [9], it may decrease the solubility of the activator components of the solution [10], and is not a suitable approach for the preparation of activating solutions for geopolymers. Carbonate solutions have been used to activate high calcium slags [11], but for less reactive aluminosilicates such as class $\mathrm{F}$ fly ashes, higher alkalinity is required.

Rice hull ash (RHA) is a pozzolanic material that has not been widely studied in geopolymer application. Rice hull is an agricultural waste that constitutes about one-fifth of the more than 600 million tonnes of rice produced annually in the world [12]. Unburnt rice hull has a very low density $\left(90-150 \mathrm{~kg} / \mathrm{m}^{3}\right)$ and, therefore, has a large dry volume, and its rough and abrasive surface is very resistant to natural degradation. The cement and concrete industry can help in the disposal of this solid waste by consuming large quantities of it [13]. Initially, rice hulls are burnt into ash in open combustors at temperatures ranging from 300 to $450^{\circ} \mathrm{C}$ [14]. If the conversion to ash occurs via uncontrolled burning below $500^{\circ} \mathrm{C}$, the incomplete ignition leaves unburned carbon in the RHA. Having more than $30 \%$ carbon has negative effects on the pozzolanic properties of RHA [14]. The silica content of RHA can be in both amorphous and crystalline forms depending on the temperature and duration of burning [15]. The concrete industry has used RHA for utilising wastes, reducing costs, enhancing the microstructure, reducing the permeability and increasing the sulphate resistance of the concrete $[16,17]$. In geopolymer technology, RHA has been used to replace the aluminosilicate source partially to adjust the $\mathrm{Si} / \mathrm{Al}$ ratio of geopolymer gel $[18,19]$ or has been dissolved in $\mathrm{NaOH}$ solution to make an economical alternative to sodium silicate activating solutions [20]. In the study here, RHA is used as the sole solid silicate source for making one-part mix geopolymers.

Solid sodium silicate and sodium aluminate are utilised in making one-part mixtures similar to Portland cement [21]. Koloušek et al. [22] have also developed new one-part mix geopolymers by calcination of metakaolin together with powdered hydroxides. One-part geopolymers are usually made by aluminosilicate precursors that are blended with solid activators [21, 23], containing a high amount of alkalis [24], or activated together with alkaline materials [25]. Although these investigations have been conducted regarding the synthesis of one-part mix geopolymers, much more study is required to understand the mechanism of geopolymer gel formation, and characterisation of geopolymer properties, in one-part mixtures. In this paper, solid sodium aluminate is used as the alumina and alkali source in activating RHA to make one-part mix geopolymers. The crystalline phases that develop in geopolymer mixtures, the microand nano-structure of binders, and the mechanical strengths of the final one-part mix geopolymers are studied and compared. 


\section{Experimental procedures}

Rice hull used in this research was sourced from Sunrice, Griffith, NSW, Australia. In order to produce rice hull ash, rice hull was burnt in a laboratory furnace at $400{ }^{\circ} \mathrm{C}$. The temperature was controlled to start from

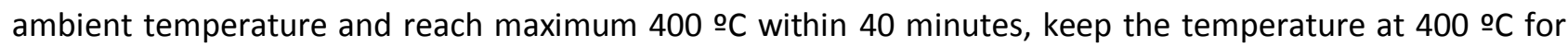
one hour, and cool down to 25 으 within 40 minutes. The resulting RHA was grinded with a mortar and pestle. A Malvern Mastersizer 2000 laser-diffraction particle-size analyser was used for measuring the particle size distribution of RHA , and the result indicated having very fine particles $\left(d_{50}=8 \mu \mathrm{m}\right)$. The effect of particle size distribution in dissolution rate of RHA is studied before [26]. Fine particles result in a very high dissolution rate of RHA in alkaline solutions and make it a very suitable source of silica in geopolymer systems [26].

The result of X-Ray Fluorescence (XRF) analysis of RHA is presented in Table 1. In order to make one-part geopolymer mixtures, RHA (as a solid silica source) was mixed with solid sodium aluminate to attain Si/Al molar ratios of $1.5: 1$ and 2.5:1, then water was added to these solid mixtures to attain samples with effective $\mathrm{H}_{2} \mathrm{O}: \mathrm{Na}_{2} \mathrm{O}$ molar ratios of $12: 1$ and $14: 1$. The $\mathrm{Na} / \mathrm{Al}$ molar ratio was kept constant at 1.27 for all the samples studied here, as this was the composition of the solid sodium aluminate source used. Solid powders were first dry mixed by hand for 1 minute. Then, water was added to the dry mix and the paste was mixed for one minute by hand followed by five minutes mixing with Hobart mixer at the rotating speed of $300 \mathrm{rev} / \mathrm{min}$.

Table 1. The oxide weight percentage composition of rice hull ash. LOI is the percentage loss on ignition at $1000^{\circ} \mathrm{C}$.

\begin{tabular}{|c|c|c|c|c|c|c|c|c|c|}
\hline $\mathrm{SiO}_{2}$ & $\mathrm{TiO}_{2}$ & $\mathrm{Fe}_{2} \mathrm{O}_{3}$ & $\mathrm{MnO}$ & $\mathrm{MgO}$ & $\mathrm{CaO}$ & $\mathrm{K}_{2} \mathrm{O}$ & $\mathrm{P}_{2} \mathrm{O}_{5}$ & $\mathrm{Al}_{2} \mathrm{O}_{3}$ & LOI \\
\hline 56.22 & 0.01 & 0.02 & 0.10 & 0.11 & 0.29 & 2.34 & 0.34 & 0.0 & 40.42 \\
\hline
\end{tabular}

Calculations are based on the silica content of RHA, as shown in the XRF results. The samples are named according to these two ratios. The number outside parentheses refers to the Si/Al molar ratio, and the number in the parentheses is the $\mathrm{H}_{2} \mathrm{O} / \mathrm{Na}_{2} \mathrm{O}$ molar ratio. So, for instance, sample RHA 1.5(12) is the RHA based geopolymer sample with the Si/Al ratio of 1.5 and an $\mathrm{H}_{2} \mathrm{O} / \mathrm{Na}_{2} \mathrm{O}$ molar ratio of 12 . Table 2 shows sample formulations on a mass basis. 
Table 2. Mass \% of each component in the samples studied here.

\begin{tabular}{|l|ccc|}
\cline { 2 - 4 } \multicolumn{1}{c|}{} & RHA & Sodium aluminate & Water \\
\hline RHA 1.5(12) & 41.1 & 23.7 & 35.2 \\
RHA 1.5(14) & 38.8 & 22.3 & 38.8 \\
RHA 2.5(14) & 51.4 & 17.8 & 30.8 \\
\hline
\end{tabular}

Crystalline phases of the samples were studied using X-Ray Diffraction (XRD) technique. XRD powder diffractograms of geopolymer specimens are collected on a Philips PW 1800 diffractometer with CuKa Xrays generated at $30 \mathrm{~mA}$ and $40 \mathrm{kV}$ with $0.0202 \theta$ steps, $2 \mathrm{~s} \mathrm{step}^{-1}$. Phase identification was carried out by comparing diffraction patterns to the ICDD PDF4 database from the International Centre for Diffraction Data, using Jade 7 software, version 5.1.2600, from Materials Data Inc.

The nanostructure of samples was analysed using the attenuated total reflectance (ATR)-FTIR method. ATRFTIR spectra were collected using a Varian FTS 7000 FT-IR spectrometer, with a Specac MKII Golden Gate single reflectance diamond ATR attachment with KRS-5 lenses and heater top plate. Absorbance spectra were collected from $4000-400 \mathrm{~cm}^{-1}$ at a resolution of $2 \mathrm{~cm}^{-1}$ and a scanning speed of $5 \mathrm{kHz}$ with 32 scans.

The microstructure of samples is examined by Scanning Electron Microscopy (SEM). SEM is performed using a Philips XL30 field emission gun scanning electron microscope (FEG-SEM) with an accelerating voltage of $20 \mathrm{kV}$. Fractured and polished specimens are mounted on stubs using adhesive carbon pads and gold coated before analysis. For the preparation of polished surfaces, samples are cut with a diamond saw, then polished with increasing fineness up to $6 \mu \mathrm{m}$ diamond paste, using the same polishing technique as applied previously for the study of geopolymers by electron microscopy [27].

The mechanical strength of geopolymers is also measured using an ELE ADRAuto 1500 compression testing machine, with $50 \mathrm{~mm}$ mortar cubes. Geopolymer pastes are mixed with standard quartz sand, with 2 grams of sand per gram geopolymer (calculated as solid plus solution), molded, vibrated for 10 seconds, sealed and cured in an oven at $40 \circ \mathrm{C}$ for the entire 108 days of experiments. Sand is added to the paste in order to improve the strength of the RHA geopolymer samples and in order to attain some comparable results with common cement mortars. Other than storing samples in slightly elevated temperature $(40 \stackrel{\circ}{ })$, the other conditions such as humidity and pressure are similar to ambient conditions. Samples are loaded in the testing instrument at a rate of $0.5 \mathrm{kN} / \mathrm{sec}$ until failure. Strengths reported are the average of three samples. 


\section{Results and Discussion}

\subsection{Characterising crystalline phases}

Figure 1 shows the XRD diffractograms of RHA-based geopolymer samples cured for different lengths of time. The crystalline phases in this figure are identified as zeolite $A$ (approximately $\mathrm{Na}_{2} \mathrm{Al}_{2} \mathrm{Si}_{1.85} \mathrm{O}_{7.7} \cdot 5 \mathrm{H}_{2} \mathrm{O}$; PDF: 00-038-0241), zeolite $X$ (approximately $\mathrm{Na}_{2} \mathrm{Al}_{2} \mathrm{Si}_{2.4} \mathrm{O}_{8.8} \cdot 6.7 \mathrm{H}_{2} \mathrm{O}$; PDF 00-012-0246), natrite $\left(\mathrm{Na}_{3.893}\left(\mathrm{CO}_{3}\right)_{2}\right.$; PDF: 05-001-0288), jadeite ( $\mathrm{NaAlSi}_{2} \mathrm{O}_{6} ;$ PDF: 00-022-1338), Sodium carbonate ( $\mathrm{Na}_{4}\left(\mathrm{CO}_{4}\right)$; PDF: 01-076-3917), diaspore (AlO(OH); PDF: 01-072-1475), gibbsite $\left(\mathrm{Al}(\mathrm{OH})_{3} ; \mathrm{PDF}: 00-033-0018\right)$ and trona $\left(\mathrm{Na}_{3} \mathrm{H}\left(\mathrm{CO}_{3}\right)_{2} \cdot 2 \mathrm{H}_{2} \mathrm{O}\right.$; PDF: 00-029-1447). The formation of carbonates can be attributed to improper sealing of the samples, which allows atmospheric $\mathrm{CO}_{2}$ to react with the sodium of the pore solutions to deposit carbonates. Sodium aluminate, as the alumina and alkali source for these geopolymers, readily dissolves [28]. However, the slower dissolution of silica from RHA does not provide enough silicate species to interact with the aluminium and sodium present in solution in the early stages of the reaction. Therefore, these systems are particularly prone to carbonation.

In RHA samples, which keep a higher degree of amorphicity during the reaction, increasing water content increases the crystallinity of the product. The higher amount of carbonates in the lower water content sample (Figure 1a) after two weeks is related to improper sealing of the sample. However, from the results after 21 and 108 days, it is obvious that a higher water content leads to more crystalline material. Zeolite $\mathrm{X}$ is the main crystal phase observed in the RHA samples. There is no obvious difference in the crystallinity of RHA sample by increasing their Si/Al ratio. In RHA 2.5(14) sample (Figure 1c) no major changes happening over time. The extent of crystallisation remains constant in this sample.

The high amount of carbon in rice hull ash is known to affect its pozzolanic activity as a supplementary material in Portland cement concretes [29]. It is obvious that by increasing the amount of carbon in the silica source, the percentage of soluble silica decreases. Here, in adjusting the Si/Al ratio in samples, a high enough RHA content is used to provide the required amount of silica for the reaction. The presence of unburnt carbon in geopolymer systems can also influence water demand due to the absorption of water by unburnt carbon, and also leads to a requirement for higher activator content because some of the activator can become sorbed onto the carbon instead of being active in the geopolymerisation reaction process.

When carbon is expelled during the combustion of rice hulls to form RHA, it leaves voids in silica particles that lead to the formation of porous material, which has a high surface area for reaction [30]. Thus, the 
high carbon content of rice hull ash significantly affects its dissolution rate, and consequently affects the reactivity of this silica source by influencing its active surface area and surface chemistry. On the other hand, the XRD pattern of the raw RHA is amorphous and the particle size analysis shows raw RHA has very fine particles. Therefore, generally higher dissolution rate and more reactivity of RHA is expected here compare to the crystalline RHA sources with larger particles. Differences in the types of crystals forming in geopolymer mixes, the extent of crystallinity in geopolymer samples, and the time when the crystals form in the samples, all show that there are differences in the kinetics of geopolymer formation with the different mix designs studied. Other analytical techniques are required here to study the kinetics of the reaction in more detail.

\subsection{Nanostructural analysis}

In FTIR studies of geopolymer systems, the main Si-O-T (T: tetrahedral Si or Al) stretching band is very important as it carries some useful information about the chemistry of developing geopolymers. The position of this band gives an indication of the length and angle of the Si-O-T bonds in the silicate network, and for amorphous silica this peak occurs at approximately $1100 \mathrm{~cm}^{-1}$ [31]. This region is attributed mainly to the stretching vibration of inner $\mathrm{SiO}_{2}$ groups [32].

Figure 2 shows the results of FTIR analysis of RHA -based geopolymers. Comparing the nanostructures of these samples shows the differences between their geopolymer networks. Figure 2(a) shows the FTIR spectra of the samples after one day. The shift of the main Si-O-T band from $1040 \mathrm{~cm}^{-1}$ to around $950 \mathrm{~cm}^{-1}$ for all samples verifies the incorporation of $\mathrm{Si}$ and $\mathrm{Al}$ in their geopolymer network. The results for all samples look very similar. The only clear difference is the shift of the main peak to lower wavenumbers in the RHA 1.5(12) and 1.5 (14) samples, which is clearer in Figure 2(b). At time zero, the main Si-O-T band for all RHA samples stands between 1000 and $1010 \mathrm{~cm}^{-1}$ wavenumbers. This is much lower than the position of the main band in amorphous RHA particles $\left(1040 \mathrm{~cm}^{-1}\right)$. Geopolymerisation reaction starts with hydrolysis reactions when most of the dissolution occurs. It is very unlikely that geopolymer gel formation starts from the beginning of the process, and this big change in the main band position at time zero suggests that the amount of silica particles that are readily dissolved immediately after mixing (i.e. within the time taken between mixing and collection of the 'time zero' data set, which is approximately five minutes) is significantly high.

During the first day of reaction, the main Si-O-T band shifts to $963 \mathrm{~cm}^{-1}$ for the RHA $2.5(14)$ sample, and to $945 \mathrm{~cm}^{-1}$ for the RHA 1.5(12) and 1.5 (14) samples, with lower Si/Al ratios. Later, as the reaction proceeds, this band shifts back to higher wavenumbers for all samples. Comparing the 1.5(12) and 1.5(14) samples, 
with different water contents, shows that the main band shifts to almost the same position in both samples. However, their shifts back to higher wavenumbers are different, with the sample with higher water content reaching higher wavenumbers. This observation suggests that the amount of Al participation and the formation of non-bridging oxygens are similar in both samples in the early stages of the reaction. This behaviour of RHA-based geopolymers was unexpected in comparison with geothermal silica-based one-part mixtures [21]. In geothermal silica-based geopolymers, the sample with higher water content showed fewer changes in the nanostructure of the silica particles.

In high carbon RHA, silica forms around carbon particles as the rice hulls burn, and carbon only escapes from this structure at high temperatures, leaving voids in the RHA particles. During the removal of carbon matter from rice RHA particles (in low carbon RHA), micropores widen or collapse resulting in an increase in mesopores [33]. Therefore in high carbon RHA particles, a relatively lower surface area is available for reaction, and consequently a lower general dissolution rate of this material in comparison with geothermal silica. Therefore, after mixing the RHA and alumina sources here, the amount of silica that is in direct contact with the alkali activator and available $\mathrm{Al}$ is not as high as geothermal silica systems. In the later stages of the reaction, by the formation of the geopolymer network and the participation of silica in this network, there will be enough driving force (i.e. silica concentration gradient) to cause the further dissolution of silica particles partially coated with carbon particles, and thus more participation of silica in the geopolymer network. However, upon increasing the amount of water present, this process happens more slowly. For the RHA sample with a higher amount of water, the main band shifts to lower wavenumbers just after mixing, as a higher amount of water provides more Al readily dissolved to react with the available silica. However, as the alkalinity is lower in this sample, it takes more time for silica to become dissolved and to form stable oligomers with Al. Consequently, further dissolution of silica will be slower in comparison to the lower water content sample.

As a result, the 1.5(14) sample starts its reaction process with more participation of Al in the newly formed gel, but less Si will be available in this sample after a few days of reaction, causing its main band to remain at lower wavenumbers than the lower water content sample, 1.5(12), for the first few days of reaction (Figure 2b). Later, when geopolymer gel forms and the driving force becomes high enough to promote further dissolution of silica from RHA, the silica released into the solution meets a lower amount of alumina available for reaction in comparison with the lower water content sample. So, the Si/Al ratio in the parts of the geopolymer network forming later in this sample will be higher than in the lower water content sample, causing the shift back to higher wavenumbers of its main band in the later stages of the reaction.

These findings match very well with the changes observed in the XRD analysis of these samples (Figure 1). As in the sample with higher water content, zeolite $X$ crystals that have lower Si/Al ratios form crystals in 
the early stages of reaction, but after a long time, jadeite phase appear in this sample, with relatively higher Si/Al ratio.

Comparing the 1.5(14) and 2.5(14) samples shows that the wavenumber of the main band is higher in the RHA 2.5(14) with higher Si/Al ratio. A higher amount of silica in the initial formulation of 2.5(14) sample has led to more participation of $\mathrm{Si}$ in its geopolymer network which causes the shift of the main band to higher wavenumbers. Although higher Si content causes more participation of $\mathrm{Si}$ in the geopolymer network for the RHA sample set studied here, most of the Al nutrients available in solution also take part in the geopolymerisation reaction in the high Si/Al ratio sample. In this sample, RHA 2.5(14), there is a high level of participation of both $\mathrm{Si}$ and $\mathrm{Al}$ nutrients in the geopolymer network, and the primary reason for the higher amount of Si observed through different stages of the reaction is the higher amount of this element in the initial mixture.

\subsection{Microstructural analysis}

The durability of a cement structure strongly depends on its physical properties, such as permeability and ionic diffusivity, which are controlled by the microstructural characteristics of cement paste. The porosity and pore size distribution are vital components of the microstructure of cement paste. The pore structure determines the permeability of cement, and thus the extent of penetration by aggressive agents [34]. In order to study the microstructure of the geopolymers synthesised here, scanning electron microscopy (SEM) is used. Figure 3 shows the results of this analysis for RHA geopolymers. Since the amount of solid sodium aluminate is quite high in all three formulas, and it readily dissolves in water after mixing, these formulas are generally creating more porous structures comparing to usual geopolymer systems.

An obvious difference can be observed between samples with different water contents. The percentage of porosity and the pore size diameter increase with increasing the water content (Figures 3b). A lower percentage of porosity and smaller size of the pores enable a material to resist chemical attack better, as it leads to lower permeability. Resistance to chloride penetration of mortar and concrete is one of the most important issues regarding the durability of concrete structures. In traditional two-part geopolymer systems, the microstructure changes from containing large pores to being more homogeneous with small pores as the Si/Al ratio increases [8]. Comparing the results for the samples with different Si/Al ratios here shows the same behaviour in the one part system. As silicate solutions are usually used to increase the Si/AI ratio of geopolymers, this shows that the substitution of RHA as a solid silica source was successful in manipulating the composition of the geopolymer mix to control the microstructural properties of the hardened binder. 
RHA has a loss on ignition of about $40 \%$, which is mainly related to its unburned carbon content. This means that if a specific amount of silica is required, almost $40 \%$ more RHA (by mass) is needed to provide the same amount of silica when compared to geothermal silica systems [21]. The more solid material used to make geopolymers, the more water is required to make a workable paste. In order to achieve high strength, low permeability, and high durability, it is necessary to control microstructure and reduce the porosity of cement paste. In the systems using solid silica sources, water requirement is a very important issue since the necessary high surface area of the solid (required to obtain sufficient reactivity) increases the water demand of the system. Therefore, by increasing the silica to alumina ratio to favour better pore structure, there will be more water required to make a suitable paste. This can then negatively affect the microstructure. So, a very careful design of solid mixtures is required to be able to manipulate the properties of the final binder, and the work presented here provides valuable preliminary steps towards achieving this aim.

\subsection{Mechanical strength}

Figure 4 shows the result of compressive strength analysis of RHA geopolymer samples. The mechanical strength of RHA samples decreases with increasing water content. This can be explained by the larger formation of pores which act as defects. Also, the mechanical strength increases with increasing the Si/Al ratio of RHA. This is because of more participation of $\mathrm{Si}$ in the geopolymer network (observed in FTIR studies) which is known to be an important parameter in the later stages of strength development in geopolymers [35]. The RHA geopolymers studied here have very low strength in the first week but then became stronger over time. The only RHA sample that gained a relatively high strength in the first week is the sample with low water content.

As was explained earlier, RHA particles release their silica content slowly. Particularly with the high amount of water required to make a workable paste from high carbon RHA materials, there will be lower alkalinity, and it takes a long time for silica and alumina species to make the stable nuclei required for further geopolymerisation reactions. However, as the reaction proceeds, when a significant amount of soluble $\mathrm{Si}$ can take part in gel formation in the later stages of the reaction, there will be a greater driving force for further silica dissolution. A higher amount of silica, therefore, dissolves in the later stages of the reaction, providing the high silica content required in the later stages of strength development [35]. Maximum strength achieved for RHA one-part mixtures is 22MPa after three weeks.

One-part mix systems have been previously made with thermal treatment of solid sources and activators using high temperatures $\left(800-1150^{\circ} \mathrm{C}\right)$, and various strength results of $1 \mathrm{MPa}$ after seven days [22], $10 \mathrm{MPa}$ 
after seven days [24], 31.5 MPa after 28 days [36], 40MPa after 28 days [25], and $47 \mathrm{MPa}$ after 28 days [37] were achieved. However, the high temperature required for calcination methods limits their commercial viability and increases their negative environmental impact. Some efforts of blending aluminosilicate source materials with solid activators have been also made to make one-part mix systems. In this approach, ambient temperature or slightly higher curing temperatures are usually used to synthesise one-part mix binders.

Yang et al. and Yang and Song used sodium silicate powder or combination of solid sodium silicate with sodium hydroxide to activate the pure fly ash and pure slag systems at ambient temperature [38, 39]. With the pure slag system, the resulting binder gained 50MPa, and the pure fly ash system gained up to $9.45 \mathrm{MPa}$ strength after 28 days. Later Nematollahi et al. activated the different combination of fly ash, slag and hydrated lime systems using different grades of sodium silicate activators [23]. They compared the strength results of one-part mixtures with a control two-part mix sample, and they could make one-part mix formulae that achieved over $37 \mathrm{MPa}$ strength at ambient temperature. Comparing the strength result of RHA geopolymer system in this study with previous attempts for making one-part mix designs, show that the strength of $22 \mathrm{MPa}$ is in an acceptable range for a solid reactant based geopolymer system that is prepared in slightly higher temperature than ambient temperature.

\section{Conclusions}

Synthesis of a one part mix geopolymers from RHA and solid sodium aluminate has been investigated. Water plays a critical role during geopolymerisation. Samples with high water content have a greater extent of crystallite formation, similar to the trends observed in 'traditional' geopolymer systems. Increasing the amount of water generally causes lower alkalinity and a slower reaction process in the system, as well as giving a more porous microstructure, which is not desirable. However, in order to make a workable paste, a high water content is unavoidable for the high carbon RHA system studied here. Increasing the silica content of the raw material blend while keeping constant alkalinity, can lead to an increase in the Si/Al ratio in the final binder, and therefore, can enhance the strength and microstructural properties of the RHA geopolymer.

Using high carbon RHA to make geopolymers adds difficulty to the analysis of the kinetics of the reaction process, as the unburned carbon content of ash particles affects the rate of release of silica, and the silica concentration alone is not a good representation of silica availability for reaction in this sample. However, 
this study shows that high carbon RHA can be used to make one-part mix geopolymers with acceptable strength development. High temperatures (between $500^{\circ} \mathrm{C}$ and $900^{\circ} \mathrm{C}$ ) are required to produce low carbon RHA with amorphous silica [40]. However, high temperature treatment of source materials increases the negative environmental impact of binder, and it is not desirable. This study shows that high carbon RHA can be a relevant substitute of silica sources without further thermal treatments.

Future studies on RHA-based geopolymers can focus on further steps towards developing viable geopolymer systems from high carbon RHA source material. Using a combination of source materials or activators can bring some flexibility in formula design and improve the performance of the binders. Using a combination of activators such as sodium hydroxide and sodium aluminate or adding some aluminosilicate sources can help with better controlling the molar ratios of the mixtures and improve structural properties of the system.

\section{Acknowledgement}

This work was funded in part by the Centre for Sustainable Resource Processing through the Geopolymer Alliance, and in part by the Australian Research Council (including partial support through the Particulate Fluids Processing Centre). The authors would like to acknowledge the guidance of Professor John L. Provis of the University of Sheffield during the course of this research.

\section{Literature Cited}

1. Provis, J.L. and J.S.J. van Deventer, Geopolymers: Structure, Processing, Properties and Industrial Applications. 2009, UK: Abington

2. van Jaarsveld, J.G.S., J.S.J. van Deventer, and L. Lorenzen, The potential use of geopolymeric materials to immobilise toxic metals: Part I. Theory and applications. Minerals Engineering, 1997. 10(7): p. 659-669.

3. Phair, J.W., Green chemistry for sustainable cement production and use. Green Chemistry, 2006. 8: p. $763-780$.

4. van Deventer, J.S.J., J.L. Provis, P. Duxson, and D.G. Brice, Chemical research and climate change as drivers in the commercial adoption of alkali activated materials. Waste and Biomass Valorization, 2010. 1: p. 145-155. 
5. Palomo, A., M.W. Grutzeck, and M.T. Blanco, Alkali-activated fly ashes: A cement for the future. Cement and Concrete Research, 1999. 29(8): p. 1323-1329.

6. Lloyd, R.R., J.L. Provis, and J.S.J. van Deventer, Microscopy and microanalysis of inorganic polymer cements. 2: The gel binder. Journal of Materials Science, 2009. 44: p. 620-631.

7. Fernández-Jiménez, A. and A. Palomo, Characterisation of fly ashes. Potential reactivity as alkaline cements. Fuel, 2003. 82(18): p. 2259-2265.

8. Duxson, P., J.L. Provis, G.C. Lukey, S.W. Mallicoat, W.M. Kriven, and J.S.J. van Deventer, Understanding the relationship between geopolymer composition, microstructure and mechanical properties. Colloids and Surfaces A: Physicochemical and Engineering Aspects, 2005. 269(1-3): p. 47-58.

9. Yang, X., W. Zhu, and Q. Yang, The viscosity properties of sodium silicate solutions. Journal of solution Chemistry, 2008. 37: p. 73-83.

10. Vail, J.G., Soluble silicates: their properties and uses 1952, New York: Reinhold.

11. Shi, C., P.V. Krivenko, and D.M. Roy, Alkali-activated cement and concretes. 2006, Abingdon, UK: Taylor and Francis.

12. Habeeb, G.A. and M.M. Fayyadh, Rice husk ash concrete: The effect of RHA average particle size on mechanical properties and drying shrinkage. Australian Journal of Basic and Applied Sciences, 2009. 3(3): p. 1616-1622.

13. Chandra, S., Waste materials used in concrete manufacturing 1997, Westwood, N.J., U.S.A. : Noyes Publications.

14. Ganesan, K., K. Rajagopal, and K. Thangavel, Rice husk ash blended cement: Assessment of optimal level of replacement for strength and permeability properties of concrete. Construction and Building Materials, 2008. 22( ): p. 1675-1683.

15. Chindaprasirt, P., C. Jaturapitakkul, and U. Rattanasak, Influence of fineness of rice husk ash and additives on the properties of lightweight aggregate. Fuel 2009. 88: p. 158-162.

16. Chindaprasirt, P., S. Homwuttiwong, and C. Jaturapitakkul, Strength and water permeability of concrete containing palm oil fuel ash and rice husk-bark ash. Construction and Building Materials, 2007. 21(7): p. 1492-1499.

17. Ajiwe, V.I.E., C.A. Okeke, and F.C. Akigwe, A preliminary study of manufacture of cement from rice husk ash. Bioresource Technology, 2000. 73(1): p. 37-39.

18. He, J., Y. Jie, J. Zhang, Y. Yu, and G. Zhang, Synthesis and characterization of red mud and rice husk ash-based geopolymer composites. Cement \& Concrete Composites 2013. 37: p. 108-118.

19. Kusbiantoro, A., M.F. Nuruddin, N. Shafiq, and S.A. Qazi, The effect of microwave incinerated rice husk ash on the compressive and bond strength of fly ash based geopolymer concrete. Construction and Building Materials 2012. 36: p. 695-703.

20. Bouzón, N., J. Payá, M.V. Borrachero, L. Soriano, M.M. Tashima, and J. Monzó, Refluxed rice husk ash/NaOH suspension for preparing alkali activated binders. Materials Letters, 2014. 115: p. 72-74. 
21. Hajimohammadi, A., J.L. Provis, and J.S.J. van Deventer, One-part geopolymer mixes from geothermal silica and sodium aluminate. Industrial and Engineering Chemistry Research, 2008. 47: p. 9396-9405.

22. Koloušek, D., J. Brus, M. Urbanova, J. Andertova, V. Hulinsky, and J. Vorel, Preparation, structure and hydrothermal stability of alternative (sodium silicate-free) geopolymers. Journal of Materials Science, 2007. 42: p. 9267-9275.

23. Nematollahi, B., J. Sanjayan, and F.U.A. Shaikh, Synthesis ofheat and ambient cured one-part geopolymer mixes with different grades of sodiumsilicate. Ceramics International 2015. 41: p. 56965704.

24. Ke, X., S.A. Bernal, N. Ye, J.L. Provis, and J. Yang, One-Part Geopolymers Based on Thermally Treated Red Mud/NaOH Blends. Journal of American Ceramic Society, 2015. 98(1): p. 5-11.

25. Feng, D., J.L. Provis, and J.S.J. van Deventer, Thermal Activation of Albite for the Synthesis of OnePart Mix Geopolymers. Journal of American Ceramic Society, 2012. 95(2): p. 565-572.

26. Hajimohammadi, A. and J.S.J. van Deventer, Dissolution behaviour of source materials for synthesis of geopolymer binders: A kinetic approach. International Journal of Mineral Processing, 2016. 153: p. 80-86.

27. Lloyd, R.R., J.L. Provis, and J.S.J. van Deventer, Microscopy and microanalysis of inorganic polymer cements.1: Remnant fly ash particles. Journal of Materials Science, 2009. 44: p. 608-619.

28. Rees, C., Mechanisms and Kinetics of Gel Formation in Geopolymers. 2007, Ph.D. Thesis, University of Melbourne.

29. Bui, D.D., J. Hu, and P. Stroeven, Particle size effect on the strength of rice husk ash blended gapgraded Portland cement concrete. Cement \& Concrete Composites 2005. 27: p. 357-366.

30. Nair, D.G., A. Fraaij, A.A.K. Klaassen, and A.P.M. Kentgens, A structural investigation relating to the pozzolanic activity of rice husk ashes. Cement and Concrete Research, 2008. 38: p. 861-869.

31. Handke, M. and W. Mozgawa, Vibrational spectroscopy of the amorphous silicates. Vibrational Spectroscopy, 1993. 5(1): p. 75-84.

32. Osswald, J. and K.T. Fehr, FTIR spectroscopic study on liquid silica solutions and nanoscale particle size determination. Journal of Materials Science 2006. 41: p. 1335-1339.

33. Liou, T.-H., Evolution of chemistry and morphology during the carbonization and combustion of rice husk. Carbon, 2004. 42(4): p. 785-794.

34. Lafhaj, Z., M. Goueygou, A. Djerbi, and M. Kaczmarek, Correlation between porosity, permeability and ultrasonic parameters of mortar with variable water / cement ratio and water content. Cement and Concrete Research 2006. 36: p. 625 - 633.

35. Fernández-Jiménez, A., A.G. de la Torre, A. Palomo, G. López-Olmo, M.M. Alonso, and M.A.G. Aranda, Quantitative determination of phases in the alkaline activation of fly ash. Part II: Degree of reaction. Fuel, 2006. 85(14-15): p. 1960-1969. 
36. Ye, N., J. Yang, S. Liang, Y. Hu, J. Hu, B. Xiao, and Q. Huang, Synthesis and strength optimization of one-part geopolymer based on red mud. Construction and Building Materials, 2016. 111: p. 317325.

37. Peng, M.X., Z.H. Wang, S.H. Shen, and Q.G. Xiao, Synthesis, characterization and mechanisms of one-part geopolymeric cement by calcining low-quality kaolin with alkali. Materials and Structures, 2014. 48(3): p. 699-708.

38. Yang, K.H. and J.K. Song, Workability loss and compressive strength development of cementless mortars activated by combination of sodium silicate and sodium hydroxide. Journal of Materials in Civil Engineering, 2009. 119: p. 119-127.

39. Yang, K.H., J.K. Song, A.F. Ashour, and E.T. Lee, Properties of cementless mortars activated by sodium silicate. Construction and Building Materials, 2008. 22: p. 1981-1989.

40. Venkatanarayanan, H.K. and P.R. Rangaraju, Material Characterization Studies on Low-and HighCarbon Rice Husk Ash and Their Performance in Portland Cement Mixtures. Advances in Civil Engineering Materials, 2013. 2(1): p. 266-287.

\section{Figure 1}

(a) RHA 1.5(12)

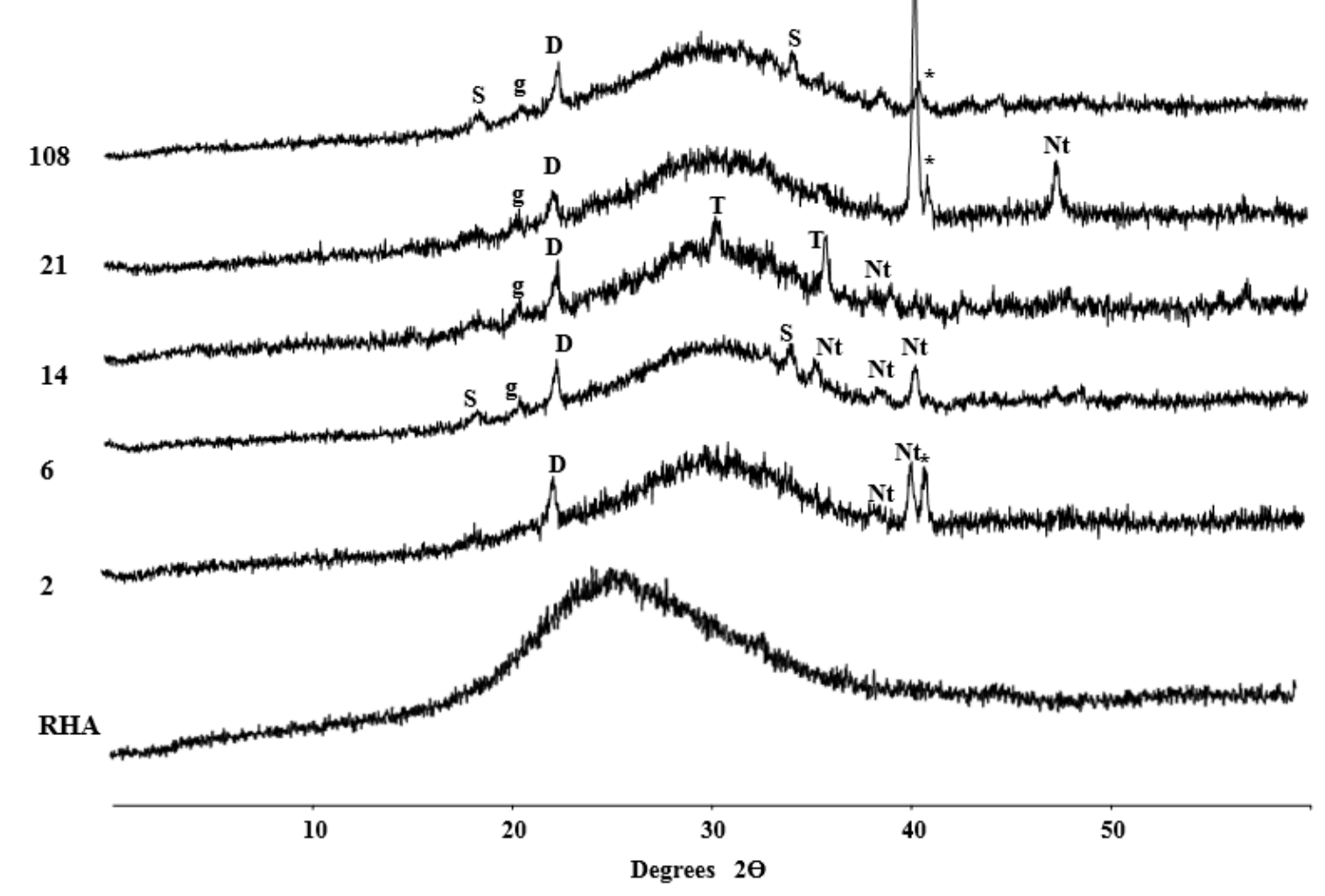


(b) RHA 1.5(14)

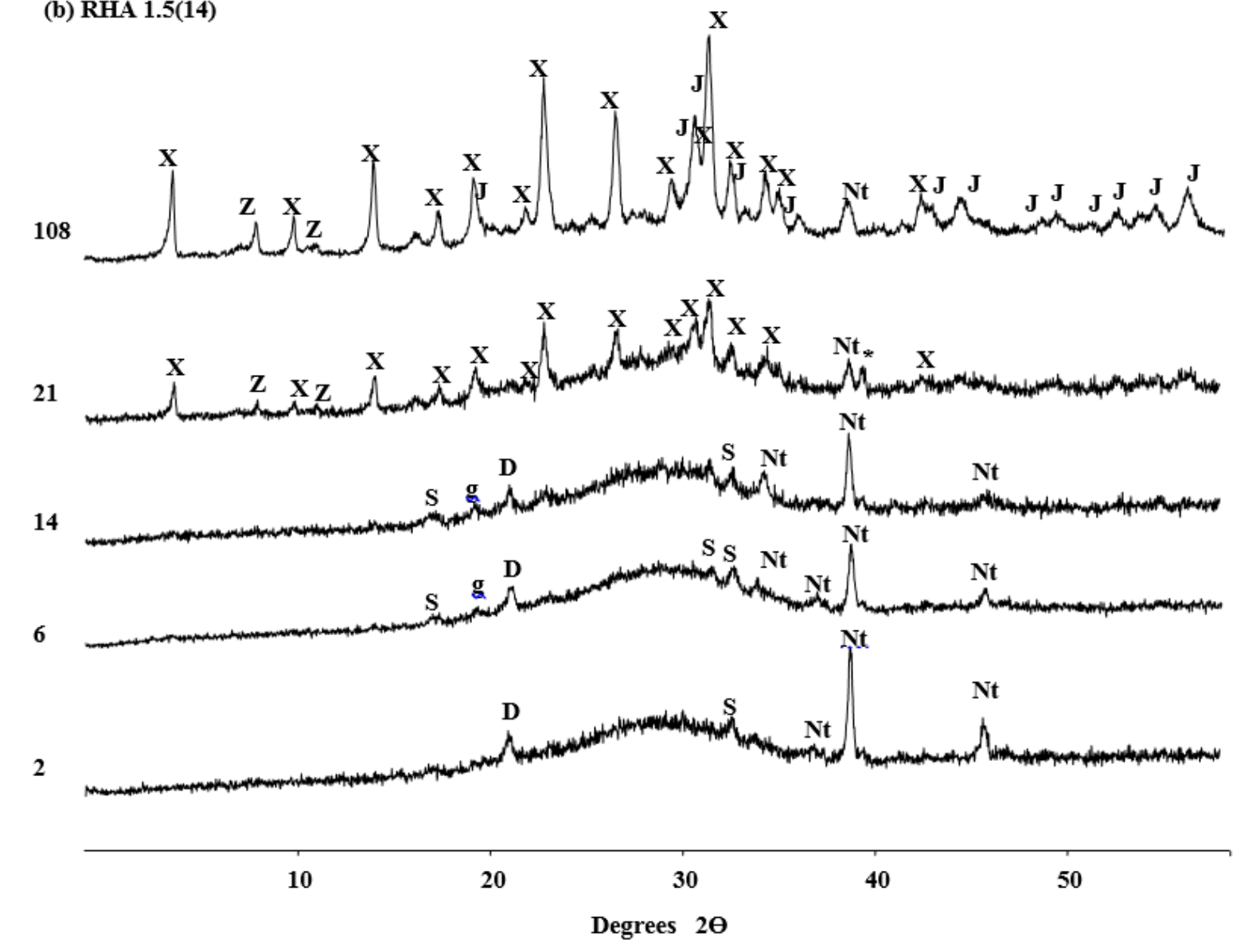

(c) RHA 2.5(14)

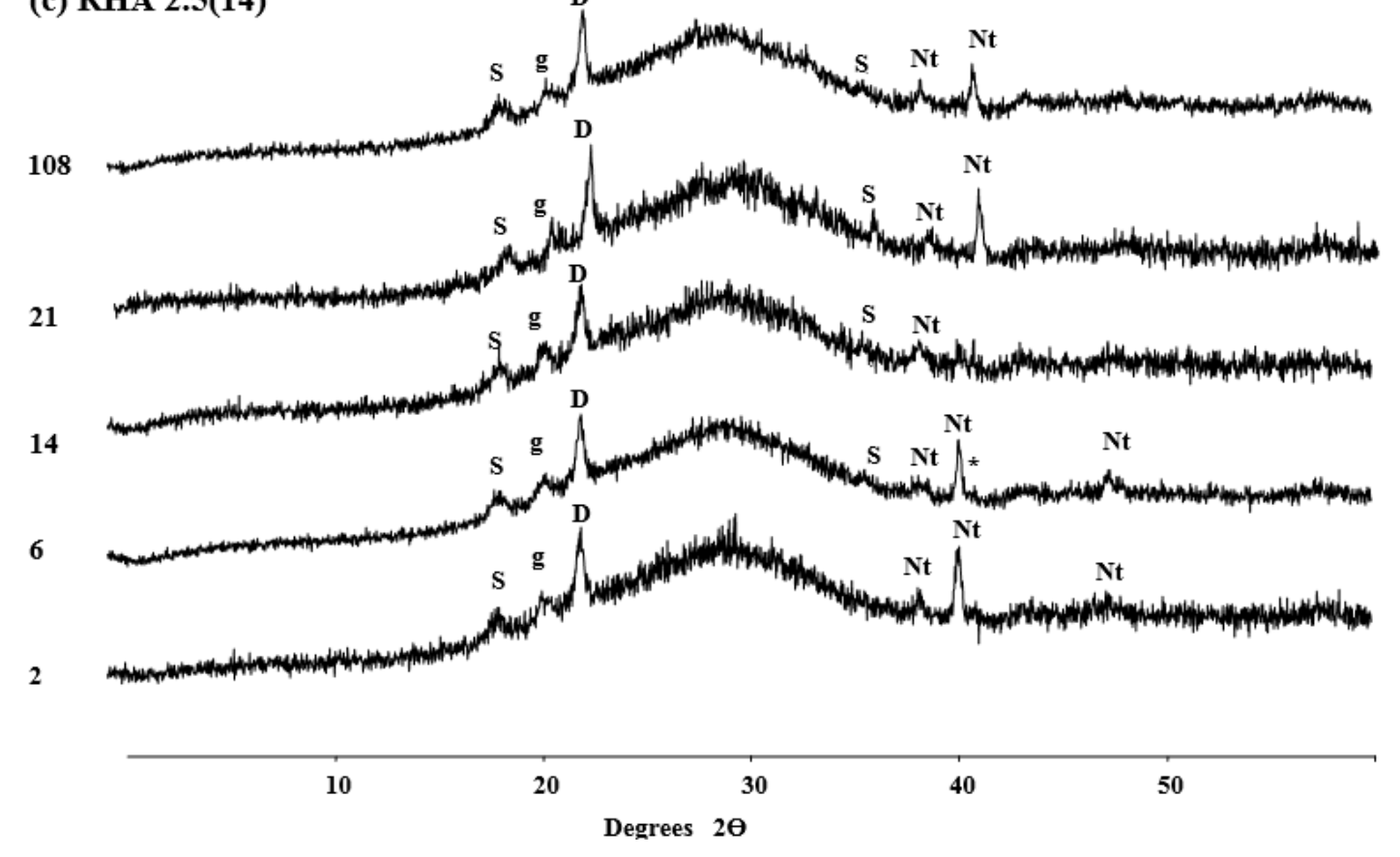


Fig. 1. Comparing XRD diffractograms of a) RHA 1.5(12), b) RHA 1.5(14) and c) RHA 2.5(14) samples over time (XRD of RHA is included in figure 1a). Numbers refer to the age of samples in days. D: Diaspore, Nt: natrite, Z: zeolite $A, X$ : zeolite $X$, J: Jadeite, $T$ : trona, g: gibbsite and $S$ : sodium carbonate. The peak marked with * is aluminium from the sample holder.

\section{Figure 2}
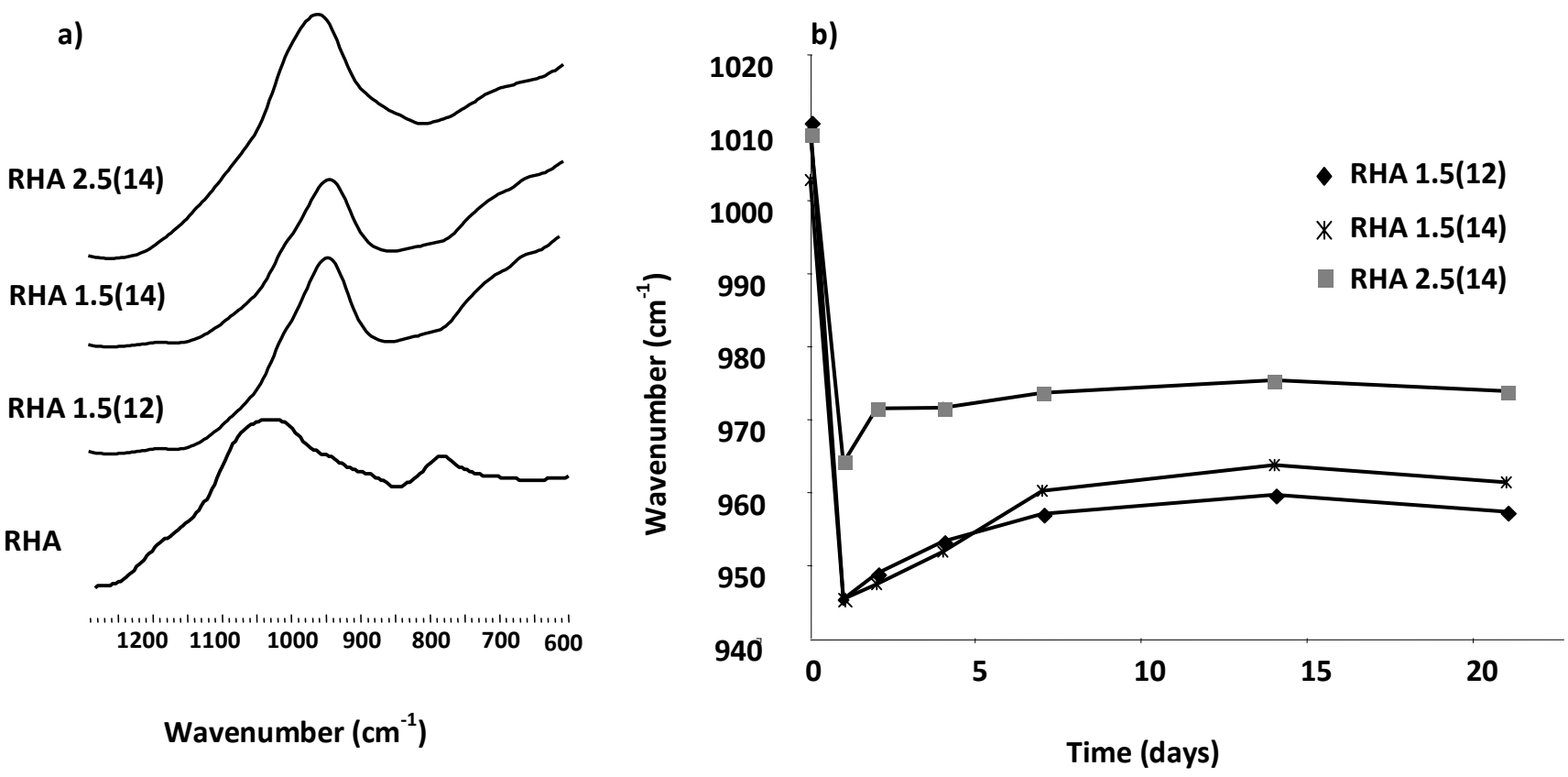

Figure 2. Ex-situ FTIR spectra of RHA and RHA-based geopolymers, a) comparing FTIR spectra after one day, and $b$ ) variation of main Si-O-T peak positions with time

\section{Figure 3}



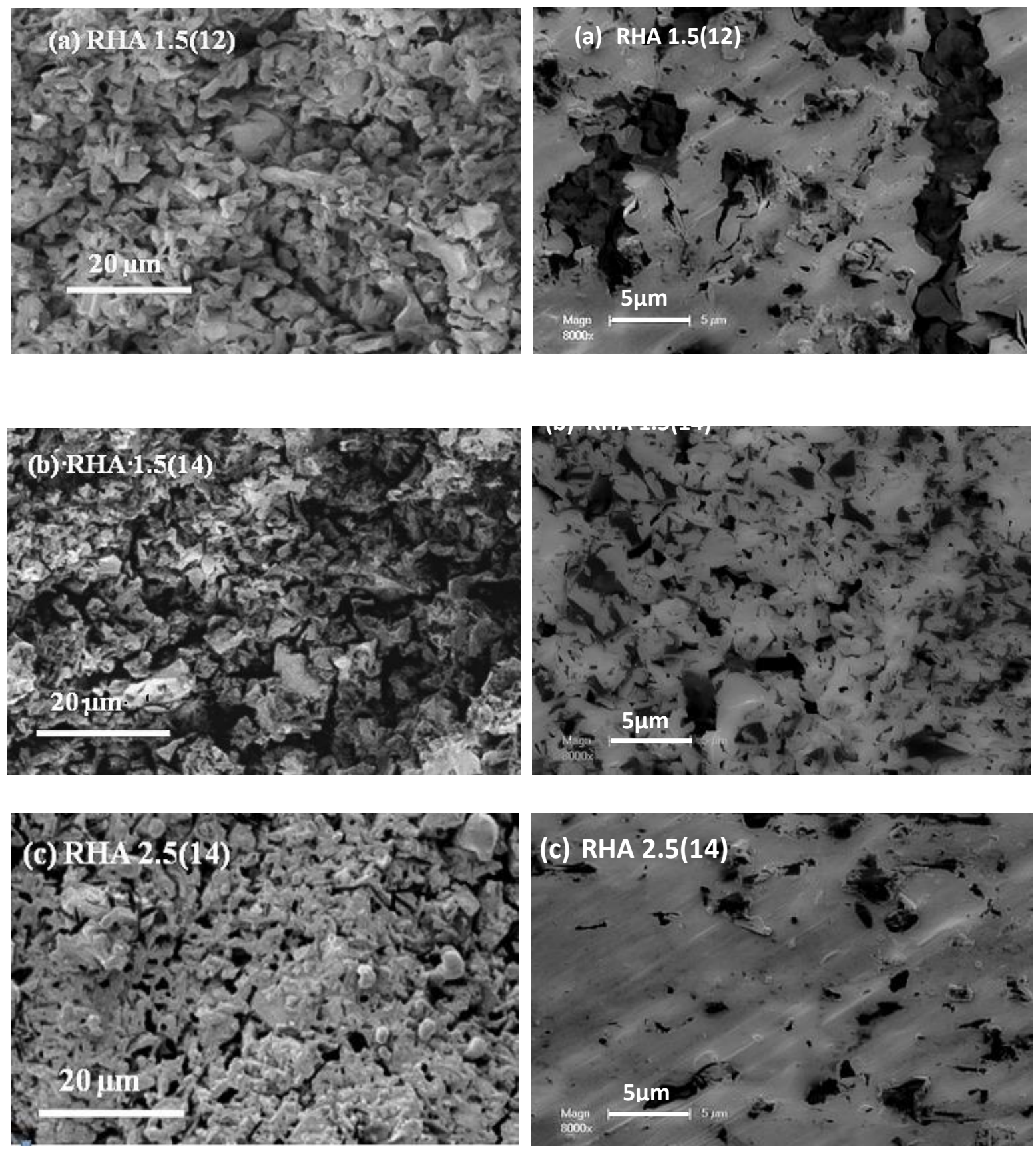

Figure 3. Scanning electron micrographs of fractured and polished surfaces of a) RHA1.5(12), b) RHA1.5(14) and c) RHA2.5(14) samples after three weeks of curing. Fractured surface images are on the left hand side and the polished surface images are on the right hand side.

Figure 4 


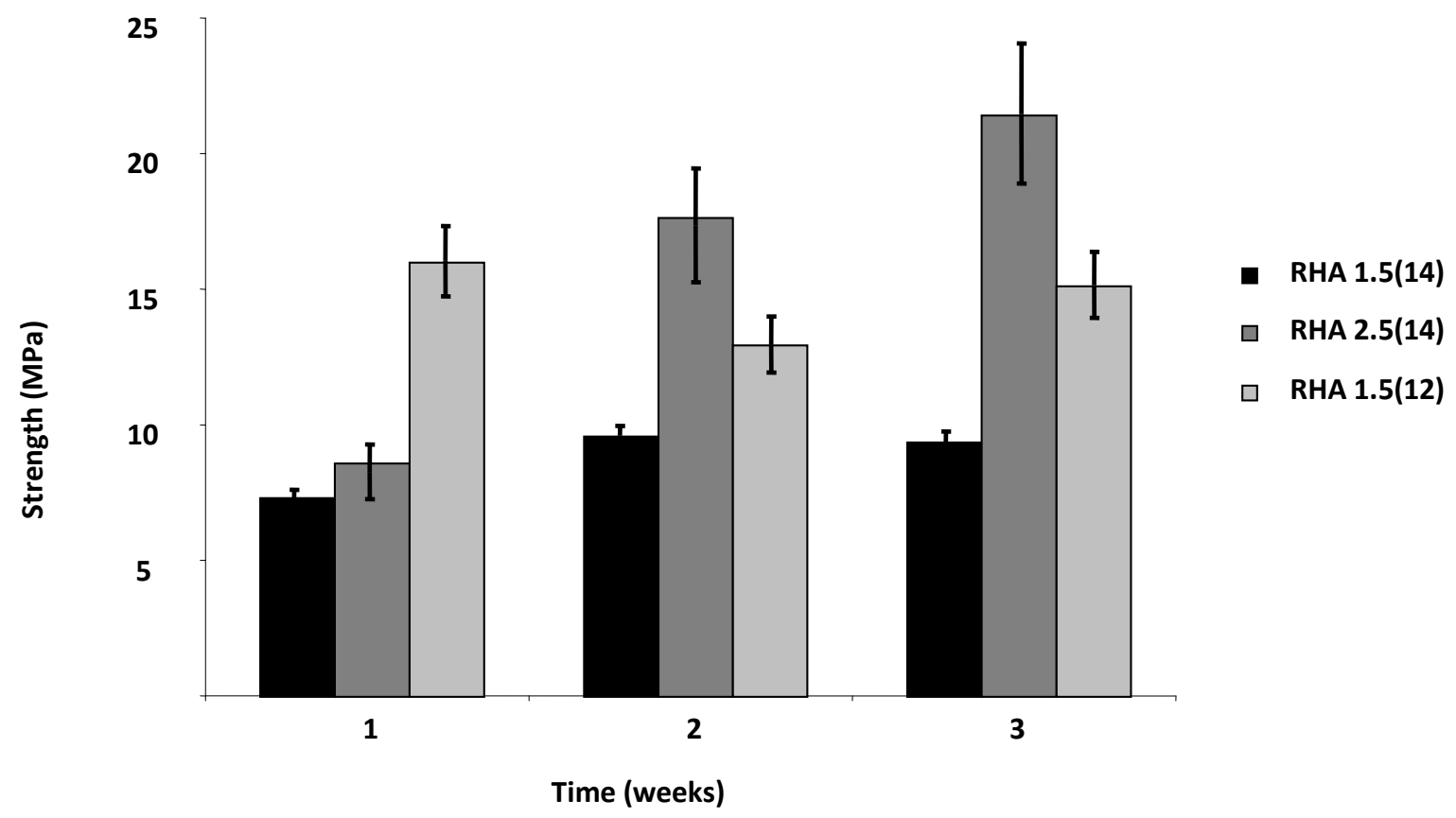

Fig. 4. Compressive strength evolution of RHA geopolymer mortars over time 


\section{University Library}

\section{- M M N E R VA A gateway to Melbourne's research publications}

Minerva Access is the Institutional Repository of The University of Melbourne

Author/s:

Hajimohammadi, A; van Deventer, JSJ

Title:

Solid Reactant-Based Geopolymers from Rice Hull Ash and Sodium Aluminate

Date:

2017-09-01

Citation:

Hajimohammadi, A. \& van Deventer, J. S. J. (2017). Solid Reactant-Based Geopolymers from Rice Hull Ash and Sodium Aluminate. WASTE AND BIOMASS VALORIZATION, 8 (6), pp.2131-2140. https://doi.org/10.1007/s12649-016-9735-6.

Persistent Link:

http://hdl.handle.net/11343/282699 